Research Article

\title{
Nonlinear Effects of Governmental and Civil Environmental Regulation on Green Total Factor Productivity in China
}

\author{
Xubin Lei $\mathbb{D}^{1}$ and Shusheng Wu $\mathbb{i D}^{2}$ \\ ${ }^{1}$ School of Economics and Trade, Hunan University, Fenglin Road, 410079 Changsha, Hunan Province, China \\ ${ }^{2}$ State Grid Hunan Electric Power Company Limited, Xinshao Dong Road, 410004 Changsha, Hunan Province, China
}

Correspondence should be addressed to Shusheng Wu; wushushengjy@163.com

Received 1 July 2019; Accepted 3 October 2019; Published 3 November 2019

Academic Editor: Herminia García Mozo

Copyright ( 2019 Xubin Lei and Shusheng Wu. This is an open access article distributed under the Creative Commons Attribution License, which permits unrestricted use, distribution, and reproduction in any medium, provided the original work is properly cited.

\begin{abstract}
This paper employs metafrontier Malmquist-Luenberger index to measure green total factor productivity and then builds panel model to investigate the nonlinear effects of both governmental and civil environmental regulation on green total factor productivity in 30 provinces of China in 2007-2016, where the threshold variables are environmental awareness and regulatory foundation. The results show that green total factor productivity takes the characteristic of cyclical fluctuation, and the magnitude and its growth rate in the eastern region are higher than those in the midwestern region. The degrees of the governmental and civil environmental regulation and green total factor productivity display single environmental awareness threshold and regulatory foundation threshold. It should be noted that the sign of governmental and civil environmental regulation on green total factor productivity will transform from negative to positive, if and only if threshold variables ascend and surpass the threshold value. Under the condition of metafrontier technology, governmental environmental awareness threshold value, based on the investigated corruption and malpractice cases by the procuratorates among every hundred thousand people, reaches 0.2158 , and civil environmental awareness threshold value based on the per capita education level will attain 12.2330 years, and the corresponding regulatory foundation index threshold values are 0.0163 and 0.0154 . These findings show clear policy implications: rather than continually promoting the level of governmental environmental regulation, civil performance, environmental awareness, and regulatory foundation should be considered.
\end{abstract}

\section{Introduction}

Since China's reform and opening-up, great achievements have been achieved based on China's rapid economic development, and residents received huge bonuses from the reform and development in the spiritual and material aspects. But backward production technology and lack of human resources lead to new growth model whose major characteristics are "high energy consumption and low energy efficiency, high input and low output," which cause extreme decrease in production resources and ecological environment deterioration. Outline of China's 13th five-year plan points out key to promote sustainable environment performance is increasing productivity, which is also the core strategy for enterprise. Market competition and government regulation are major motivations for enterprises to improve total factor productivity. In this paper, we will endeavor to explore afresh the underlying nonlinear relationship between environmental regulation and total factor productivity.

Governmental law enforcement should be primarily through discharging standards for pollutants, levying pollution tax, providing technical innovation subsidies, and improving the pollutant emission property right transaction market to carry out the regulation on enterprise [1-4]. It should be pointed out that most of researches assume that environmental regulation is equal to government-led environmental regulation, which ignores the personal role in that behavior. In fact, personal utility becomes more and more important role in environmental protection in information-based or legalization-based society, especially in 
China. As basic public resource, excellent environmental protection becomes scarce resource, while the elasticity of demand for civil healthy living tends to be lower level. Moreover, scholars presume that environmental protection law enforcement in different areas is homogeneous, which means they hold the same law enforcement utility. Taking China as an example, environmental awareness and regulatory foundation are significantly heterogeneous, which can affect the above law enforcement utility [5]. Among them, regulatory foundation reflects the regulation resistance determined by local economic structure. These pose questions for us: as for region heterogeneity of environmental regulation and regulatory foundation, can it affect the influence of environmental regulation on the green total factor productivity effect and how does one resolve the dilemma of economy growth and environmental regulation?

The remainder of this paper is organized as follows. Section 2 presents the corresponding literature review and innovation points. Section 3 denotes methodology. Section 4 is data. Section 5 presents the empirical analysis results. Section 6 concludes this paper and provides some constructive policy implications.

\section{Literature Review}

Since Porter and Linde [1] put forward Porter Hypothesis, relationship between environmental regulation and productivity becomes an important and hot study topic. Based on different research methods, different research objects, and different research data, three distinct research statements have been obtained [6-10]. (1) Hypothesis of cost competition: Becker [6] found that industries with higher environmental regulation cost have no statistically remarkable influential effect in manufacturing industries, which support the hypothesis of cost competition that enterprise innovation does not offset cost with environmental regulation. (2) Porter hypothesis: Porter and Linde [1] took the dynamic characteristic of technology innovation in econometric model and insisted that compensation earnings derived from technology innovation in the long term are bigger than the competition effect. Zhang et al. [11] used Malmquist-Luenberger index to calculate productivity and established econometric model to explore correlation between the strictness of environmental regulation and productivity and then found that positive relationships are tested in empirical analysis which support Porter Hypothesis. (3) Uncertainty hypothesis: Wang and Shen [12] adopted regulatory intension as threshold variable to analyze the nonlinear relationship between environmental regulation and total factor productivity. Results show that an "inverted U-shaped" correlation exists. Xie et al. [13] employed a panel threshold model and a province-level panel dataset during 2000-2012 to examine different types of environmental regulations and heterogeneous influence on green productivity. Research results show that both command-and-control regulation and market-based regulation have a nonlinear relationship and can be positively related to green productivity but with different constrains on regulation stringency.
These above research papers provide meaningful study perspectives to understand and analyze the correlation between governmental environmental regulation and productivity, while they seldom go to study regulatory utility of civil environmental regulation. Ebenstein [14] found that abominable environment triggered by the production pollution contributes to the enhancement of the demand and supply of civil society to protect the environment or promote the total factor productivity. Zhang et al. [15] formulated the Hybrid Luenberger index to measure regional industrial green productivity and explored whether civil environmental protection forces the growth of China's industrial green productivity or not, which shows that, compared with the intensity of environmental pollution and other passive environmental protection incentives, the public are more sensitive to per capita income level, education quality, health concern, and other rational environmental protection incentives. But, the above scholars did not take the heterogeneity of the environmental awareness and regional regulatory foundation, which is not comprehensive. In order to fill these gaps, we make the following improvements. Civil environmental regulation, environmental awareness, and regulatory foundation should be taken into account as the core explanatory variables or threshold variables.

The effective measurement of green total factor productivity is the premise and guarantee to estimate the correlation between regulation and productivity. The stochastic frontier approach (SFA) and the data envelopment analysis (DEA) are mainstream research methods. What should be highlighted is SFA hinge on model parameters, while DEA can overcome the potential error derived from the above parameters. Since Charnes et al. [16] creatively proposed linear programming to calculate efficiency or productivity, the DEA method has been far-ranging used or optimized with nonparametric measurement [17-20]. Charnes et al. [16] employed new directional distance function to enhance the measurement accuracy for productivity based on the unexpected output. DEA model contains radial situation and nonradial situation, while both of them hold information loss under the condition of using separately. Epsilon based measure (EBM) effectively covers the advantages of both radial situation and nonradial situation [21]. Moreover, most researchers assume that homogeneity is normal for enterprise productivity. Oh and Lee [22] put forward metafrontier Malmquist-Luenberger (MML) index to propose grouping frontier to measure productivity combined with metafrontier framework [23]. Reference for scholar's research, MML index is the effective and reasonable method to measure green total factor productivity.

\section{Methodology}

3.1. Econometric Model. The purpose of this paper is to study potential nonlinear relationship between environmental regulation and total factor productivity, whose method is using the cross terms of the following two aspects: environmental regulation with environmental awareness or regulation foundation to construct the threshold 
econometric model. What should be stated is that environmental awareness contains governmental environmental awareness, civil environmental awareness, enterprise environmental awareness, and social environmental awareness, while regulation foundation reflects the cost factors or marker factors, which may influence the government on how to implement environmental regulation decisionmaking. Then, infrastructure level, industrial structure, marketization level, and opening degree are chosen to construct comprehensive index to measure the regulation foundation. Moreover, studies have shown that technology research and development strength, domestic capital stock of $\mathrm{R} \& \mathrm{D}$, and foreign direct investment have significantly influence on productivity [24-26]. Considering that the green total factor productivity may have the certain continuity, a dynamic econometric model would be adopted. Taking significant volatility of economy into consideration, four econometric models are established as follows:

$$
\begin{aligned}
\mathrm{MML}_{i t}= & \alpha_{0}+\alpha_{1} \mathrm{MML}_{i t-1}+\alpha_{2} \mathrm{GER}_{i t}+\alpha_{3} \mathrm{PER}_{i t}+\alpha_{4}(\mathrm{GER} * \mathrm{FUB})_{i t} \\
& +\alpha_{5} \mathrm{QYI}_{i t}+\alpha_{6} \mathrm{RKM}_{i t}+\alpha_{7} \mathrm{RD}_{i t}+\alpha_{8} \mathrm{CRD}_{i t}+\alpha_{9} \mathrm{FDI}_{i t}+\varepsilon_{t}+\gamma_{i}+\mu_{i t}, \\
\mathrm{MML}_{i t}= & \beta_{0}+\beta_{1} \mathrm{MML}_{i t-1}+\beta_{2} \mathrm{GER}_{i t}+\beta_{3} \mathrm{PER}_{i t}+\beta_{4}(\mathrm{PER} * \mathrm{REL})_{i t}+\beta_{5} \mathrm{QYI}_{i t} \\
& +\beta_{6} \mathrm{RKM}_{i t}+\beta_{7} \mathrm{RD}_{i t}+\beta_{8} \mathrm{CRD}_{i t}+\beta_{9} \mathrm{FDI}_{i t}+\varepsilon_{t}+\gamma_{i}+\mu_{i t}, \\
\mathrm{MML}_{i t}= & \chi_{0}+\chi_{1} \mathrm{MML}_{i t-1}+\chi_{2} \mathrm{GER}_{i t}+\chi_{3} \mathrm{PER}_{i t}+\chi_{4}(\mathrm{GER} * \mathrm{REF})_{i t}+\chi_{5} \mathrm{QY}_{i t} \\
& +\chi_{6} \mathrm{RKM}_{i t}+\chi_{7} \mathrm{RD}_{i t}+\chi_{8} \mathrm{CRD}_{i t}+\chi_{9} \mathrm{FDI}_{i t}+\varepsilon_{t}+\gamma_{i}+\mu_{i t}, \\
\mathrm{MML}_{i t}= & \delta_{0}+\delta_{1} \mathrm{MML}_{i t-1}+\delta_{2} \mathrm{GER}_{i t}+\delta_{3} \mathrm{PER}_{i t}+\delta_{4}(\mathrm{PER} * \mathrm{REF})_{i t}+\delta_{5} \mathrm{QYI}_{i t} \\
& +\delta_{6} \mathrm{RKM}_{i t}+\delta_{7} \mathrm{RD}_{i t}+\delta_{8} \mathrm{CRD}_{i t}+\delta_{9} \mathrm{FDI}_{i t}+\varepsilon_{t}+\gamma_{i}+\mu_{i t},
\end{aligned}
$$

where $i$ is the province, $t$ stands for year, MML represents the green total factor productivity, GER denotes the governmental environmental regulation, PER shows the civil environmental regulation, FUB is the governmental environmental awareness, REL stands for the civil environmental awareness, REF represents the regulation foundation, QYJ denotes the enterprise environmental awareness, RKM is the social environmental awareness, RD denotes the technology research and development strength, CRD represents the domestic capital stock of R\&D, and FDI shows the foreign direct investment. Moreover, $\varepsilon_{t}$ shows the time fixed effect, $\gamma_{i}$ stands for the space fixed effect, and $\mu_{i t}$ is the error term. To weaken the volatility of the data, all variables in model (1)-(4) are in logarithmic form.

As for the parameter estimation method, least square method, fixed effect method, or random effects method will get error estimation results in the dynamic model, while generalized moment method (GMM) can effectively solve the endogenous problems of dynamic model [27]. In terms of this method, it is divided into system GMM or difference GMM based on instrumental variable and can also be decomposed into one-step GMM or two-step GMM. Windmeijer [28] found that one-step system GMM would result in effective and unbiased estimates under the circumstance of using more information. Finally, Stata 12.0 software will be used to estimate the sign and magnitude of the econometric parameters.

3.2. Method of Green Total Factor Productivity. Since scholars take undesirable output into consideration in DEA model, more and more researchers created and employed direction distance function to maximize the desirable output or minimize the undesirable output $[9,18,21,29]$. This paper supposes that there are $N$ kinds of production resources, $M$ kinds of desirable outputs, and $L$ kinds of undesirable outputs for each decision-making unit (DMU). Firstly, we refer to the definitions by Färe et al. [30]; environmental technology function is introduced as in the following production set:

$$
\begin{gathered}
P(x)=\left\{\left(X, \Upsilon^{e}, \Upsilon^{u}\right) \mid x \geq X \lambda, y^{e} \leq \Upsilon^{e}, y^{u}=\Upsilon^{u} \lambda, \lambda \geq 0\right\}, \\
X=\left(x_{1}, x_{2}, \ldots, x_{N}\right), \\
\Upsilon^{e}=\left(y_{1}^{e}, y_{2}^{e}, \ldots, y_{M}^{e}\right), \\
\Upsilon^{u}=\left(y_{1}^{u}, y_{2}^{u}, \ldots, y_{L}^{u}\right),
\end{gathered}
$$

where $P(x)$ is the environmental technology function, $x$ is the inputs of DMU, $\Upsilon^{e}$ stands for desirable outputs, and $\Upsilon^{u}$ denotes the undesirable outputs. Direction distance function is preferable to change the composition proportion of inputs for getting more desirable outputs and little undesirable outputs. Direction distance function contains radial model and nonradial model. The radial model would create unnecessary waste, and the nonradial model can make loss of useful information, which means using any of the above methods separately will result in biased estimates. Fortunately, Tone and Tsutsui [21] put forward EBM-DEA model, which can effectively solve the above hidden trouble. Secondly, taking the input orientation and variable return scale (VRS) as an example, we introduce the EBM linear programming (LP) model as follows: 


$$
\begin{aligned}
\gamma^{*} & =\min _{\vartheta, \lambda, s^{-}} \theta-\varepsilon_{x} \sum_{i=1}^{N} w_{i}^{-} s_{i}^{-} / x_{i 0}, \\
\text { s.t. } \theta x_{0}-X \lambda-s^{-} & =0, \\
\lambda Y & \geq y, \\
\lambda & \geq 0, \\
s^{-} & \geq 0,
\end{aligned}
$$

where the research object includes I DMUs, and each DMU contains $M+L$ outputs and $N$ kinds of inputs. $\gamma$ represents the optimum efficiency calculated by the above EBM model, $\theta$ stands for the radial efficiency value estimated by the CCR model [16], $s^{-}$denotes the slack variable derived from the nonradial model, $\lambda$ is the weight of each district section observation, $\varepsilon_{x}$ represents the weight value of variable, and $\omega_{i}$ denotes the parameter based on both radial and nonradial models. Following the above model and methods, the annual total factor productivity of each DMU can be measured. What need to be stated briefly is that the above measure result of productivity is static efficiency, which is unable to directly compare the productivity growth rate for the same DMU. To solve this problem, Chung et al. [29] have set
Malmquist-Luenberger (ML) index based on the definition of Malmquist index. But the hypotheses of homogeneity of the production technology in the above researches are not optimal. Oh and Lee [22] combined the metafrontier theory with DEA model to develop the metafrontier Malmquist approach. Scholars have investigated metafrontier Malmquist index or metafrontier Malmquist-Luenberger index to test the efficiency of different industries or regions [31-33]. Thirdly, the specific explanation of MML index is shown as follows. According to the production technology heterogeneity assumption of each DMU, all research objects would be divided into $K$ groups in line with a reasonable standard. As for any specific group, the production possibilities' technology reference set is $P_{t}(x)=\left\{\left(X_{t}, Y_{t}^{e}\right.\right.$, $Y_{t}^{u} \mid X$ can produce $\left.\left.Y\right)\right\}$, which is the same as formula (5). It is hinge on all DMUS of one group, and group frontier technology level belongs to the upper limit of $P_{t}(x)$. Then $K$ kinds of group frontier will be established, supposing that they abide by common technical boundary. Finally, metafrontier set can be calculated by the upper limit, which is the enveloping curve of all group frontier curves. Therefore, in line with the definition by Chen and Yang [34], the direction distance function and MML index is shown as follows:

$$
\begin{aligned}
\overrightarrow{D_{t}}\left(X^{t}, \Upsilon^{e t}, \Upsilon^{u t}\right) & =\sup \left\{\beta_{t}:\left(X^{t}, \Upsilon^{t}+\beta_{t} \Upsilon^{e t}, \Upsilon^{t}+\beta_{t} Y^{u t}\right) \in P_{t}(X)\right\}, \\
M M L & =\left\{\frac{\left[1+\overrightarrow{D_{t}}\left(X^{t}, \Upsilon^{e t}, \Upsilon^{u t}\right)\right]}{\left[1+\overrightarrow{D_{t}}\left(X^{t+1}, \Upsilon^{e t+1}, \Upsilon^{u t+1}\right)\right]} \times \frac{\left[1+\overrightarrow{D_{t+1}}\left(X^{t}, \Upsilon^{e t}, \Upsilon^{u t}\right)\right]}{\left[1+\overrightarrow{D_{t+1}}\left(X^{t+1}, \Upsilon^{e t+1}, \Upsilon^{u t+1}\right)\right]}\right\}^{1 / 2},
\end{aligned}
$$

where MML index belongs to the dynamic value of green total factor productivity, MML $>1$ denotes that the green total factor productivity is improving, and $M M L<1$ denotes that green total factor productivity is decreasing.

\section{Data}

4.1. Inputs and Outputs of Green Total Factor Productivity. Appropriately choosing input factors and output factors is a crucial precondition for calculating green total factor productivity based on metafrontier Malmquist-Luenberger index. Five kinds of variables have been selected. In line with $\mathrm{Li}$ and $\mathrm{Wu}[9]$, input variables include labor force and capital stock and energy consumption, while output variables contain real gross domestic product (GDP) and undesirable pollutants. The effective labor per unit time is an optimal approach to measure labor force, while because of data deficiency the quantity of labor force is a constructive method. This paper uses the total number of tertiary industries, secondary industries, and primary industries, with the specific industry classification being established by China's national industries classification (GB/T 4754-2002). Labor force data is collected from the provincial statistical yearbook and China statistical yearbook. In terms of capital stock, perpetual inventory approach is reasonable. The formula is $K_{t}=I_{t}+(1-a) K_{t-1}$, where $K_{t}$ is the capital stock of $t$ period, $I_{t}$ denotes the fixed assets investment of $t$ period, and $a$ stands for the rate of depreciation. Moreover, the detailed process of measuring the capital stock is given by Shan [35], and we eliminate the price factor at the constant 2007 prices of fixed assets' investment. The above relevant data can be gained from China statistical yearbook. As for energy consumption, in view of each DMU's energy consumption, the structure takes a degree of difference, whose energy consumption can be estimated by the consumption of standard coal based on convert coefficients of fossil energy. The fossil energy contains coal, coke, crude oil, kerosene, fuel oil, gasoline, diesel, and natural gas, whose corresponding convert coefficients are 0.7143, 0.9714, $1.4826,1.4714,1.4286,1.4714,1.4571$, and 1.3300 , respectively. Data of 2016 is inquired from China energy statistical yearbook, while other data is collected from China statistical yearbook. The gross domestic product can be directly retrieved from China statistical yearbook, and it is calculated at 2004 prices. Undesirable pollutants conclude discharge of industrial waste solid, discharge of industrial waste gas, and discharge volume of industrial waste water, and the specific data is collected from China statistical 
yearbook. Based on the data availability and continuity, 30 provinces, municipalities, and autonomous regions are perfect research objects, and the time dimension is from 2007 to 2016. Referring to the Chinese traditional division method, the research object is divided into three groups, which are east region, central region, and west region. Table 1 shows input-output factors' definitions and descriptive statistics. Table 2 contains the detailed division and measurement of green total factor productivity growth ratio from 2007 to 2016. According to Table 2, green total factor productivity of east region is increasing, while the corresponding productivity of middle region and west region is falling based on the average value. The differentiation of productivity levels and variation tendency enlightens that the government should implement differentiation policy.

\subsection{Core Explanatory Variables and Control Explanatory} Variables. Core explanatory variables contain environmental regulation level, environmental awareness, and environmental regulation foundation. In terms of regulation level, governmental environmental regulation can be calculated by the ratio of pollution abatement cost or investment to the industrial value added $[2,3]$. The data can be collected from China environmental statistics yearbook. Civil environmental regulation can be measured by personal income level that is estimated by GDP per capita [9]. The data is obtained from China statistics yearbook. As for environmental awareness, some scholars found that environmental awareness of consumer or manager can affect enterprise decision on innovation [36]. Referring to researches from Simsekli [37], education level of labor force, entrepreneur innovative spirit, and population density can be used to measure civil environmental awareness, enterprise environmental awareness, and social environmental awareness. Corresponding data is derived from China statistics yearbook, China labor statistical yearbook, and China science and technology statistic yearbook. Due to the difficult measurement of governmental environmental awareness, few scholars investigate it in the econometric model. This paper uses substitution variable that holds a high correlation with it, and based on the investigation by the people's procuratorates, the number of corruption and bribery and malfeasance in one hundred thousand people can calculate the governmental environmental awareness. The data is collected from China procuratorial yearbook and annual work report of the people's procuratorates. Then, the regulation foundation is measured by comprehensive index, which contains infrastructure level, industrial structure, marketization level, and opening degree. This paper adopts road area per capita, ratio of the second industry output to GDP, rate of private sector employment number to total employment number, and percent of import and export output to GDP, and entropy evaluation method can be employed to measure the variable weight and regulation foundation value. All the relevant data comes from China statistic yearbook.

In this paper, three control variables conclude the technology research and development strength, domestic capital stock of R\&D, and foreign direct investment. In particular, the cost of technology research and development in government, civil society, or enterprise can improve the technical level, increase customer experience utility, shorten the industrial and regional gap, and enhance residents' happiness index $[24,25]$. This paper uses the cost strength and level of $R \& D$, and the data can be directly retrieved from China statistic yearbook. Moreover, foreign direct investment generates technology spillovers from host country to local country, which is conducive to introduce advanced enterprise management experiences, leading production technology, regional leadership, and market power [38]. It thence appears that FDI should be taken into econometric model, and the data is derived from China statistic yearbook. Table 3 shows the descriptions of all variables.

\section{Empirical Analysis Results}

5.1. Threshold Effect Analysis of Governmental and Civil Environmental Awareness. Table 4 shows the regression results of nonlinear effect model whose threshold variables are governmental and civil awareness. In order to present the time effect and individual effect, results of year fixed effect model, results of space fixed effect model, and results of space and year fixed effect model are shown in Table 4. Specifically, M1, M2, and M3 denote the regression results of governmental environmental awareness, and M4 and M5 stand for the results of civil environmental awareness. It is clear that the coefficient signs between LnPER and LnGER $\times$ LnFUB, LnPER and LnPER $\times$ LnREL are different, which justifies the reasonable choice of nonlinear model. In terms of hypothesis testing results for GMM in the following six models, results of residual serial correlation test $(A R(2))$ show that there is no second-order serial correlation in model residuals, and statistics of Sargan test show that instrumental variable set is reasonable.

As shown in column 2 to column 4 or column 5 to column 7 in Table 4, the magnitude and sign of coefficients are remarkably consistent, while the significance levels of coefficients in column 4 or column 7 better than others which means that space and year fixed effect is applied. As for the governmental environmental awareness in column 2 to column 4, the coefficients of L. LnMML are 0.0268, 0.0375, and 0.1010 and significant at $10 \%$ significance level, which means that $1 \%$ increase in green total factor productivity this year will induce $0.0268 \%, 0.0375 \%$, or $0.1010 \%$ increase next year. The implementations of macroeconomic policy have certain cycle and certain hysteresis effect. Once the adjustment change of management institutions occurs, the established macropolicy enforcement will be discounted. So, the effect of L. LnMML on MML enlightens that the management institutions should keep continuity of the policy moderately. Similarly, in terms of civil environmental awareness in column 5 to column 7, coefficients of L. LnMML are $0.0475,0.0113$, and 0.0620 , which means that $1 \%$ increase in local green total factor productivity this year will lead to $0.0475 \%, 0.0113 \%$, and $0.0620 \%$ increase next year. Government should continue to adhere to the 
TABLE 1: Input-output factors' definitions and descriptive statistics.

\begin{tabular}{|c|c|c|c|c|c|c|c|}
\hline & Definition & Observation & Mean & $\begin{array}{l}\text { Standard } \\
\text { deviation }\end{array}$ & Minimum & Maximum & Unit \\
\hline \multirow{3}{*}{ Inputs } & Labor force & 300 & 2519.543 & 1685.913 & 290.42 & 6580.4 & Ten thousand people \\
\hline & Capital stock & 300 & 20101.67 & 19910 & 547.3055 & 114443.8 & $\begin{array}{l}\text { Hundred million } \\
\text { RMB }\end{array}$ \\
\hline & Energy consumption & 300 & 11685.08 & 7708.388 & 742 & 39423 & Ten thousand tons \\
\hline \multirow{4}{*}{ Outputs } & Real gross domestic product & 300 & 12477.19 & 11379.99 & 466.1 & 62474.79 & Million RMB \\
\hline & Discharge of industrial waste gas & 300 & 765232.4 & 448834.4 & 22000 & 2002000 & Ton \\
\hline & $\begin{array}{c}\text { Discharge of industrial waste } \\
\text { water }\end{array}$ & 300 & 196388.6 & 156083.9 & 14287 & 862471.1 & Ton \\
\hline & Discharge of industrial waste solid & 300 & 7316.967 & 6987.782 & 112 & 45575.83 & Ton \\
\hline
\end{tabular}

TABLE 2: Green total factor productivity growth ratio in 2007-2016.

\begin{tabular}{|c|c|c|c|c|c|c|c|c|c|c|}
\hline Zone & Province & 07/08 & 08/09 & $09 / 10$ & $10 / 11$ & $11 / 12$ & $12 / 13$ & $13 / 14$ & $14 / 15$ & $15 / 16$ \\
\hline \multirow{12}{*}{ East region } & Beijing & 0.9943 & 0.9998 & 1.0019 & 1.0014 & 1.0032 & 1.0017 & 1.0037 & 1.0004 & 1.0012 \\
\hline & Tianjin & 1.0000 & 0.9958 & 0.9940 & 1.0103 & 0.9952 & 1.0004 & 1.0043 & 1.0000 & 1.0000 \\
\hline & Hebei & 0.9968 & 0.9966 & 0.9998 & 0.9943 & 0.9954 & 1.0060 & 1.0112 & 1.0000 & 1.0000 \\
\hline & Liaoning & 1.0000 & 1.0000 & 1.0000 & 0.9947 & 0.9956 & 0.9979 & 1.0118 & 1.0000 & 1.0000 \\
\hline & Shanghai & 0.9968 & 1.0033 & 1.0000 & 1.0000 & 0.9973 & 1.0027 & 1.0000 & 1.0000 & 1.0000 \\
\hline & Jiangsu & 1.0000 & 0.9987 & 0.9967 & 1.0000 & 0.9976 & 1.0026 & 1.0043 & 1.0000 & 1.0000 \\
\hline & Zhejiang & 0.9981 & 1.0004 & 0.9995 & 1.0015 & 0.9987 & 1.0057 & 1.0049 & 1.0005 & 0.9996 \\
\hline & Fujian & 0.9928 & 0.9964 & 1.0018 & 1.0011 & 1.0014 & 1.0021 & 0.9994 & 1.0015 & 1.0007 \\
\hline & Shandong & 1.0000 & 1.0000 & 0.9949 & 0.9990 & 0.9959 & 1.0024 & 1.0078 & 1.0000 & 1.0000 \\
\hline & Guangdong & 1.0000 & 0.9978 & 1.0022 & 1.0000 & 0.9970 & 1.0030 & 1.0000 & 1.0000 & 1.0000 \\
\hline & Hainan & 0.9946 & 0.9984 & 0.9983 & 1.0088 & 0.9921 & 1.0080 & 1.0000 & 1.0000 & 1.0000 \\
\hline & Average & 0.9976 & 0.9988 & 0.9990 & 1.0010 & 0.9972 & 1.0030 & 1.0043 & 1.0002 & 1.0001 \\
\hline \multirow{9}{*}{ Middle region } & Shanxi & 1.0000 & 0.9942 & 0.9983 & 0.9994 & 0.9925 & 1.0052 & 1.0105 & 1.0000 & 1.0000 \\
\hline & Jilin & 0.9819 & 0.9958 & 0.9996 & 0.9996 & 0.9995 & 1.0066 & 1.0103 & 1.0010 & 1.0003 \\
\hline & Heilongjiang & 0.9816 & 0.9889 & 0.9973 & 1.0014 & 0.9938 & 1.0021 & 1.0088 & 0.9984 & 0.9954 \\
\hline & Anhui & 0.9856 & 0.9960 & 1.0002 & 1.0038 & 0.9978 & 1.0030 & 1.0146 & 1.0009 & 0.9997 \\
\hline & Jiangxi & 1.0000 & 1.0000 & 0.9985 & 1.0015 & 0.9926 & 1.0013 & 1.0061 & 1.0000 & 1.0000 \\
\hline & Henan & 1.0106 & 0.9938 & 0.9989 & 0.9972 & 0.9957 & 1.0009 & 1.0059 & 1.0003 & 1.0000 \\
\hline & Hubei & 0.9897 & 0.9969 & 1.0015 & 1.0037 & 0.9992 & 1.0055 & 1.0063 & 0.9985 & 1.0005 \\
\hline & Hunan & 0.9807 & 0.9980 & 1.0027 & 1.0012 & 0.9986 & 1.0026 & 1.0084 & 0.9989 & 0.9981 \\
\hline & Average & 0.9913 & 0.9955 & 0.9996 & 1.0010 & 0.9962 & 1.0034 & 1.0089 & 0.9998 & 0.9993 \\
\hline \multirow{12}{*}{ West region } & Inner Mongolia & 1.0000 & 1.0000 & 0.9984 & 1.0016 & 0.9966 & 1.0035 & 1.0000 & 1.0000 & 0.9964 \\
\hline & Guangxi & 1.0000 & 0.9960 & 1.0041 & 1.0000 & 0.9946 & 1.0054 & 0.9828 & 1.0040 & 0.9941 \\
\hline & Chongqing & 0.9917 & 0.9957 & 0.9946 & 1.0020 & 0.9974 & 0.9994 & 0.9969 & 0.9997 & 1.0002 \\
\hline & Sichuan & 0.9888 & 0.9936 & 0.9986 & 0.9987 & 0.9961 & 1.0045 & 0.9984 & 1.0011 & 1.0007 \\
\hline & Guizhou & 1.0000 & 1.0000 & 0.9938 & 0.9936 & 1.0000 & 0.9997 & 0.9930 & 0.9972 & 0.9996 \\
\hline & Yunnan & 0.9750 & 0.9992 & 1.0032 & 1.0035 & 0.9959 & 1.0019 & 1.0408 & 0.9865 & 0.9965 \\
\hline & Shanxi & 1.0008 & 0.9995 & 0.9999 & 1.0039 & 0.9933 & 1.0034 & 1.0118 & 0.9991 & 1.0009 \\
\hline & Gansu & 0.9692 & 0.9936 & 0.9967 & 1.0001 & 0.9970 & 1.0075 & 1.0150 & 0.9959 & 0.9962 \\
\hline & Qinghai & 1.0000 & 0.9949 & 0.9988 & 1.0064 & 1.0000 & 1.0000 & 1.0000 & 1.0000 & 1.0000 \\
\hline & Ningxia & 1.0000 & 1.0000 & 1.0000 & 1.0000 & 0.9955 & 1.0045 & 1.0000 & 1.0000 & 1.0000 \\
\hline & Xinjiang & 0.9913 & 0.9967 & 1.0031 & 1.0018 & 0.9972 & 1.0037 & 1.0072 & 0.9980 & 0.9984 \\
\hline & Average & 0.9924 & 0.9972 & 0.9992 & 1.0011 & 0.9967 & 1.0030 & 1.0042 & 0.9983 & 0.9985 \\
\hline
\end{tabular}

environmental protection education to enhance local productivity.

The effects of governmental environmental regulation on green total factor productivity are dependent on the regulation stringency and governmental environmental awareness in column 2 to column 4 . The coefficients of LnGER are -0.0241 in column 4 and significant at $1 \%$ significance level, and the corresponding coefficient of $\operatorname{LnGER} \times \operatorname{LnFUB}$ is 0.0052 and significant at $5 \%$ significance level. The above regression results suggest that the government environmental awareness has single threshold when it comes to consider the effect of governmental environmental regulation on green total factor productivity, and the threshold value is 4.6346 ; namely, corruption and bribery and malfeasance number based on an investigation by the people's procuratorates in every one hundred thousand people is 0.2158 . According to the measure data of the government environmental awareness, the sample range in various areas of China in corruption and bribery and malfeasance number based on an investigation by the people's procuratorates in one hundred 
TABLE 3: Descriptions of all variables.

\begin{tabular}{lcccccc}
\hline Definition & Variable & Mean & Standard deviation & Minimum & Maximum & Unit \\
\hline Green total factor productivity & MML & 0.9996 & 0.0056 & 0.9692 & 1.0408 & - \\
\hline Governmental environmental regulation & GER & 0.0435 & 0.0344 & 0.0036 & 0.2692 & - \\
Civil environmental regulation & PER & 22407.0 & 14291.2 & 4070.0 & 74420.9 & RMB \\
\hline Governmental environmental awareness & FUB & 2.7522 & 0.7056 & 1.4316 & 5.9069 & - \\
Civil environmental awareness & REL & 8.5728 & 0.9926 & 6.3778 & 12.027 & Year \\
Enterprise environmental awareness & QYJ & 0.1701 & 0.1131 & 0.0264 & 0.6777 & - \\
Social environmental awareness & RKM & 2523.7 & 1388.2 & 186.00 & 6307.0 & - \\
\hline Infrastructure level & GZJC & 12.180 & 3.8706 & 4.0400 & 25.3400 & - \\
Industrial structure & CYJ & 48.230 & 7.6461 & 22.300 & 61.500 & \\
Marketization level & NOP & 0.3476 & 0.4308 & 0.0357 & 1.7991 & - \\
Opening degree & WOP & 0.2106 & 0.1162 & 0.0559 & 0.6870 & - \\
\hline Technology research and development strength & RD & 1.2902 & 1.0111 & 0.1700 & 6.0800 & - \\
Domestic capital stock of R\&D & CRD & 661.779 & 930.590 & 5.0719 & 5226.24 & Hundred million RMB \\
Foreign direct investment & FDI & 0.0253 & 0.0195 & 0.0007 & 0.0819 & - \\
\hline
\end{tabular}

TABLE 4: Regression results of nonlinear effect model (threshold variable: FUB and REL).

\begin{tabular}{|c|c|c|c|c|c|c|}
\hline Model & GER-M1 & GER-M2 & GER-M3 & PER-M4 & PER-M5 & PER-M6 \\
\hline Variable & Year fixed effect & Space fixed effect & $\begin{array}{c}\text { Space and year fixed } \\
\text { effect }\end{array}$ & Year fixed effect & Space fixed effect & $\begin{array}{c}\text { Space and year fixed } \\
\text { effect }\end{array}$ \\
\hline L. LnMML & $0268^{* *}(2.20)$ & $0.0375^{*}(1.77)$ & $0.1010^{* * *}(5.46)$ & $0.0475^{* *}(2.24)$ & $0.0113(0.55)$ & $0.0620^{* * *}(3.22)$ \\
\hline LnGER & $-0.0226^{*}(-1.76)$ & $-0.0251(-0$ & $241^{* * *}(-3.82)$ & $* *(-2.06)$ & -0.01 & $2^{* * *}(-4.73)$ \\
\hline LnPER & $0.0075(1.56)$ & $-0.0046^{* *}(-2$ & $0.0006(0.28)$ & $-0.1468^{*}(-1.69)$ & $-0.1539^{*}(-1.89)$ & $-0.1699^{*}(-1.86)$ \\
\hline LnGER $\times$ LnFUB & $0.0054^{* * *}(3.66)$ & $0.0051^{* * *}(2.79)$ & $0.0052^{* *}(2.33)$ & & & \\
\hline LnPER $\times$ LnREL & & & & $0.0137^{* * *}(5.78)$ & $0.0136^{* * *}(7.70)$ & $0.0139^{* * *}(5.53)$ \\
\hline LnQYJ & $-0.0019(-1.06)$ & $0.0031(0.02)$ & $-0.0023(-1.17)$ & $-0.0289(-0.76)$ & -0.01 & $-0.0338^{*}(-1$ \\
\hline & 7) & -0.0 & & & & 0.0 \\
\hline LnRD & $0.0037^{* * *}(4.77)$ & $0.0044^{* * *}(4.65)$ & $0.0048^{* * *}(5.09)$ & $0.0022^{* * *}(2.74)$ & $0.0028^{* * *}(2.64)$ & $0.0046^{* * *}(5.29)$ \\
\hline LnCRD & 0.0017 (1.07) & $0.0035^{* * *}(2.88)$ & $0.0013(0.98)$ & $0.0011^{*}(1.84)$ & $0.0031(1.48)$ & $0.0029^{* *}(2.10)$ \\
\hline LnFDI & $-0.0078(-0.59)$ & $0.0407(1.18)$ & $-0.0129(-0.78)$ & $-0.0148(-0.17)$ & $0.0346(1.29)$ & $-0.0173(-0.70)$ \\
\hline & $0.7146^{* * *}(32.08)$ & $0.7090^{* * *}(31.24)$ & $0.7080^{* * *}(34.87)$ & $0.6504^{* * *}(26.35)$ & $0.6470^{* * *}(24.85)$ & $0.6800^{* * *}(33.33)$ \\
\hline AR (2) & 0.1182 & 0.1901 & 0.1360 & & 0.1801 & 0.2050 \\
\hline Sargan & 0.0937 & 0.1548 & 0.1024 & 0.1174 & 0.2012 & 0.1412 \\
\hline
\end{tabular}

Note. ${ }^{* * *},{ }^{* *}$, and ${ }^{*}$ represent significance levels of $1 \%, 5 \%$, and $10 \% ; t$ values are shown in parentheses.

thousand people is greater than 0.2158 , and the minimum is 1.4316 in Shanghai in 2011. The reason is that official controls the allocation of production factors, causing serious rentseeking. In particular, the fiscal and taxation system reformed in 1994 caused fiscal decentralization between the central government and local government, while local government weaken the environmental protection for achieving political demands.

In terms of civil environmental regulation on green total factor productivity, which is also determined by civil regulation stringency and its environmental awareness in column 5 to column 7, coefficient of LnPER is negative $(-0.1699)$ and significant at $10 \%$ significance level $(t=-1.86)$, while coefficient of LnPER $\times$ LnREL is positive (0.0139) and significant at $1 \%$ significance level $(t=5.53)$. The results show that there is a single threshold of civil environmental awareness for the effect of civil environmental regulation on green total factor productivity, and the threshold value is 12.2230 , also known as that per education level should reach 12.2230 years. Unfortunately, the highest education level in data sample is Beijing in 2013, and the level is 12.0276. Before reaching the threshold, enhancing the education level can lower the disadvantageous influence.
Ascension of education level can develop personal innovation capability and awareness, which is helpful to realize sustainable development. Moreover, we further study the effect of enterprise and social awareness on productivity. Coefficients of LnQYJ in column 4 and column 7 are -0.0023 and -0.0338 , which means that $1 \%$ increase in LnQYJ will induce $0.0023 \%$ or $0.0338 \%$ decrease. Coefficients of LnRKM are positive $(0.0018,0.0087)$ and significant at $1 \%$ significance level $(t=4.78,4.97)$, which suggests that it is necessary to plan and control the urban population. Coefficients of control variables (LnRD, LnCRD, and LnFDI) in column 4 are $0.0048,0.0013$, and -0.0129 , and they are $0.0046,0.0029$, and -0.0173 in column 7 . Results show that increasing the research cost moderately will improve the researchers' study preferences and investment, while crowding-out effect is greater than positive spillover effect, both created by FDI.

5.2. Threshold Effect Analysis of Regulation Foundation. Table 5 shows the regression results of nonlinear effect model whose threshold variable is regulation foundation in year fixed effect, space fixed effect, and space and year fixed effect. M7, M8, and M9 present econometric model of 
TABLE 5: Regression results of nonlinear effect model (threshold variable: REF).

\begin{tabular}{lcccccc}
\hline Variable & Year fixed effect & Space fixed effect & $\begin{array}{c}\text { Space and year } \\
\text { fixed effect }\end{array}$ & Year fixed effect & $\begin{array}{c}\text { Space fixed effect } \\
\text { Space and year } \\
\text { fixed effect }\end{array}$ \\
\hline Model & GER-M7 & GER-M8 & GER-M9 & PER-M10 & PER-M11 & PER-M12 \\
L. LnMML & $0.0994^{* * *}(4.79)$ & $0.0224(0.09)$ & $0.1070^{* * *}(5.66)$ & $0.1116^{* *}(2.16)$ & $0.0469^{* *}(2.15)$ & $0.1030^{* * *}(5.04)$ \\
LnGER & $-0.2100^{* *}(-2.02)$ & $-0.2630^{* *}(-2.22)$ & $-0.2380^{* *}(2.21)$ & $-0.0150^{* * *}(-5.96)$ & $-0.0163^{* * *}(-4.26)$ & $-0.0234^{* * *}(-6.88)$ \\
LnPER & $-0.0022(-0.10)$ & $-0.0773^{* *}(-2.34)$ & $-0.0017(-0.07)$ & $-0.0006(-0.17)$ & $-0.0007(-0.24)$ & $-0.0006(-0.23)$ \\
LnGER $\times$ LnREF & $15.4715^{*}(1.90)$ & $17.1200^{* *}(2.46)$ & $14.5580^{*}(1.80)$ & & & \\
LnPER $\times$ LnREF & & & & $0.0415(0.96)$ & $0.0441(1.14)$ & $0.0391^{*}(1.73)$ \\
LnQYJ & $-0.0020(-0.63)$ & $0.0015(0.85)$ & $-0.0012(-0.52)$ & $-0.0015(-0.76)$ & $-0.0017(-0.75)$ & $-0.0016(-0.77)$ \\
LnRKM & $0.0751^{* *}(2.19)$ & $-0.0443(-1.49)$ & $0.0959^{* * *}(4.92)$ & $0.0099^{* *}(2.04)$ & $-0.0015(-0.67)$ & $0.0103^{* * *}(4.11)$ \\
LnRD & $0.0371^{* * *}(3.80)$ & $0.0470^{* * *}(5.01)$ & $0.0445^{* * *}(3.75)$ & $0.0410^{* * *}(3.66)$ & $0.0433^{* * *}(4.92)$ & $0.0463^{* * *}(5.09)$ \\
LnCRD & $0.0253(1.08)$ & $0.0474^{* * *}(2.85)$ & $0.0142(0.91)$ & $0.0089(1.10)$ & $0.0170(1.11)$ & $0.0121(0.78)$ \\
LnFDI & $-0.0364(-0.27)$ & $-0.0896(-0.28)$ & $-0.0473^{*}(-1.78)$ & $-0.0741(-0.32)$ & $0.0192(0.62)$ & $-0.0109(-0.61)$ \\
CONS & $0.6918^{* * *}(46.78)$ & $0.7080^{* * *}(31.62)$ & $0.7220^{* * *}(44.54)$ & $0.6677^{* * *}(37.20)$ & $0.6830^{* * *}(20.85)$ & $0.7100^{* * *}(29.14)$ \\
AR (2) & 0.2708 & 0.3362 & 0.2481 & 0.2274 & 0.2451 & 0.2548 \\
Sargan & 0.0955 & 0.1024 & 0.0874 & 0.0728 & 0.0954 & 0.0895 \\
\hline
\end{tabular}

Note. ${ }^{* * *},{ }^{* *}$, and ${ }^{*}$ represent significance levels of $1 \%, 5 \%$, and $10 \%$; $t$ values are shown in parentheses.

governmental environment regulation, and M10, M11, and M12 denote the regression results of civil environmental regulation. In terms of statistical hypothesis testing, tests of AR (2) and Sargan show that dynamic panel threshold models are rational and the endogenous problem is effectively solved.

As for regression results, coefficients of L. LnMML are $0.0994,0.0224,0.1070,0.1116,0.0469$, and 0.1030 , which means that $1 \%$ increasing in productivity this year will induce $0.0994 \%, 0.0224 \%, 0.1070 \%, 0.1116 \%, 0.0469 \%$, or $0.1030 \%$ augmentation the following year in the same region. The phenomenon and characteristic of MML index are in line with Table 4; namely, reducing the effects of policy changes on economic growth is applied. What should be pointed out is that signs of LnGER and LnGER $\times$ LnREF, LnPER and LnPER $\times$ LnREF are reversed; namely, regulation foundation can influence marginal effects of governmental or civil environmental regulation on green total factor productivity. Coefficients of LnGER and LnGER $\times$ LnREF in column 4 or LnPER and LnPER $\times$ LnREF in column 7 in Table 5 are $-0.2380,14.5580,-0.0006$, 0.0391 and significant at $10 \%$ significance level; namely, the single threshold of regulation foundation is 0.0163 and 0.0154 , respectively. Above all, we find that all comprehensive indexes of regulation foundation in 2007-2016 are less than the two threshold values. The reasons are reflected in the following several aspects. Firstly, infrastructure construction is the premise and basis of urbanization, which need a lot of support of capital and labor force. However, the status quo is narrow channels of financial income in the condition of huge population base which makes lower level of road holdings. Secondly, the layout of local industrial structure is unreasonable, which needs transformation and upgrading as soon as possible. Thirdly, the distance of the state-owned enterprise management mode and its administrative levels are not conductive to the local government implement environmental regulation. Moreover, the fiscal decentralization narrows the local government tax. The central government should promote joint-stock reform of state-owned enterprises effectively, improve enterprise efficiency, and deal with the relationship between the local state-owned enterprises and local government. Fourthly, import and export is a main driving force to promote the development of economy, and moderately weakening trade barriers and enhancing the regional economic exchanges will help to reduce transaction costs. When it comes to other control variables, coefficients of $\mathrm{LnRD}$ and LnCRD are positive $(0.0445,0.0463 ; 0.0142,0.0121)$ in column 4 and column 7, while corresponding coefficients of LnFDI are negative $(-0.0473,-0.0109)$.

\section{Conclusion and Policy Recommendation}

By controlling the technology research and development strength, domestic capital stock of $\mathrm{R} \& \mathrm{D}$, and foreign direct investment, this paper establishes dynamic panel data threshold econometric model to analyze the influence effect of governmental and civil environmental regulation on green total factor productivity in China's 30 provincial regions during 2007-2016. By conducting governmental and civil environmental awareness and regulation foundation as thresholds, we found that single threshold transformation effects significantly exist. Environmental awareness and regulation foundation take positive marginal effect on environmental regulation, which means that they can weaken the negative effect of regulation on productivity. Unfortunately, both environmental awareness and regulation foundation in all regions failed to meet the threshold value. The gap between the governmental environmental awareness and its threshold is larger than the corresponding gap between the civil environmental awareness and its threshold value, and the latter is relatively small. In terms of the calculated comprehensive index of regulation foundation and its threshold value, the marginal effect gap in governmental environmental regulation or civil environmental regulation is at a lower level. Based on this article's main research conclusions, some relevant policy recommendations are suggested as follows: 
(1) Governmental environmental regulation has not increased the green total factor productivity, mainly due to the lower level of governmental environmental awareness and regulation foundation of economic structure. Therefore, governmental environmental awareness and regulation foundation should be enhanced and optimized rather than improving the stringency of environmental regulation unilaterally. As for the environmental awareness, both regulating screening and regulating personnel assessment can improve the governmental environmental awareness. Firstly, personnel recruitment should pay attention to educational level, environmental loyalty, and subjective initiative during the government environmental protection department talent introduction. Secondly, regional environment protection efficiency, implementation of welfare, bonus, and travelling benefit should be taken into consideration during the assessment of environmental regulation personnel. Thirdly, the regulatory department should step up the environmental protection personnel corruption government malfeasance dynamic investigation. In terms of regulation foundation, according to its connotation, the construction of industrial park infrastructure, eliminating enterprises of high energy consumption and low yield of inferior quality through technical innovation to optimize local industrial structure, encouraging entrepreneurship, and accelerating the reformation of state-owned enterprise share-holding system should be employed.

(2) Government environmental regulation and civil environmental regulation produce certain effect to the green total factor productivity, and we cannot ignore the role of persons in the process of environmental regulation. Moreover, we should actively guide environmental protection organization and social individuals to actively participate in enterprise pollution control. But the effect of civil environmental regulation mainly depends on the degree of civil regulation ability and environmental awareness. On the one hand, raising personal income level and increasing donation from enterprise or private channels are crucial to enhance the civil environmental regulation cost. On the other hand, offering environmental protection courses, inviting environmental experts and environmentalists to open lecture, paying attention to environmental protection propaganda, strengthening family education, or creating environmental disaster experience service are important to promote the civil environmental awareness. In addition, civil environmental regulation should protect the legal validity of civil environmental regulation and moral binding. On one side, government should realize decentralization step by step, which contains environmental monitoring and environmental supervision and management. Only in this way, universal supervision can be achieved, and political rentseeking or economic rent-seeking will be severely suppressed. On the other side, the central government should change the promotion mechanism for local government and enhance personal participation in environmental governance.

\section{Data Availability}

The green total factor productivity, government environmental regulation, and civil environmental regulation used to support the finding of this study have been deposited in the CNKI (China National Knowledge Infrastructure) repository, and the DOI of reference paper is $10.1016 /$ j.jclepro.2016.10.042. In addition, the basic data to measure urban-rural income gap may be released upon application to China's National Bureau of Statistics or EPS database. The environmental awareness data used to support the finding of this study have been deposited in the CNKI (China National Knowledge Infrastructure) repository, and the DOI of corresponding reference paper is $10.1016 /$ j.ecolecon.2016.05.007. In addition, the data used to measure financial agglomeration for supporting the findings of this study may be released upon application to China's National Bureau of Statistics or EPS database. (3) The technology research and development strength, domestic capital stock of $\mathrm{R} \& \mathrm{D}$, and foreign direct investment data used to support the finding of this study may be released upon application to China's National Bureau of Statistics or EPS database.

\section{Conflicts of Interest}

The author declares that they have no conflicts of interest.

\section{References}

[1] M. E. Porter and C. V. D. Linde, "Toward a new conception of the environment-competitiveness relationship," Journal of Economic Perspectives, vol. 9, no. 4, pp. 97-118, 1995.

[2] J. Ederington and M. Jenny, "Is environmental policy a secondary trade barrier? An empirical analysis," Canadian Journal of Economics, vol. 36, no. 1, pp. 137-154, 2003.

[3] A. Levinson and M. S. Taylor, "Unmasking the pollution haven effect," International Economic Review, vol. 49, no. 1, pp. 223-245, 2008.

[4] Z. X. He, S. C. Xu, W. X. Shen, R. Y. Long, and H. Chen, "Factors that influence corporate environmental behavior: empirical analysis based on panel data in China," Journal of Cleaner Production, vol. 133, pp. 531-543, 2016.

[5] M. Kitzmueller and S. Jay, "Economic perspectives on corporate social responsibility," Journal of Economic Literature, vol. 50, no. 1, pp. 51-84, 2012.

[6] A. R. Becker, "Local environmental regulation and plant-level productivity," Ecological Economics, vol. 70, no. 12, pp. 2516-2522, 2011.

[7] A. Sanchez-Vargas, R. Mansilla-Sanchez, and A. AguilarIbarra, "An empirical analysis of the nonlinear relationship between environmental regulation and manufacturing productivity," Journal of Applied Economics, vol. 16, no. 2, pp. 357-371, 2013.

[8] X. Zhao and B. Sun, "The influence of Chinese environmental regulation on corporation innovation and competitiveness," Journal of Cleaner Production, vol. 112, pp. 1528-1536, 2016. 
[9] B. Li and S. S. Wu, "Carbon emission reduction effect of open trade in urbanization process," Business Economy and Management, vol. 3, pp. 22-34, 2016.

[10] B. Li and S. Wu, "Effects of local and civil environmental regulation on green total factor productivity in China: a spatial durbin econometric analysis," Journal of Cleaner Production, vol. 153, pp. 342-353, 2017.

[11] C. Zhang, H. Liu, H. T. A. Bressers, and K. S. Buchanan, "Productivity growth and environmental regulations-accounting for undesirable outputs: analysis of China's thirty provincial regions using the MalmquistLuenberger index," Ecological Economics, vol. 70, no. 12, pp. 2369-2379, 2011.

[12] Y. Wang and N. Shen, "Environmental regulation and environmental productivity: the case of China," Renewable and Sustainable Energy Reviews, vol. 62, pp. 758-766, 2016.

[13] R.-H. Xie, Y.-J. Yuan, and J.-J. Huang, "Different types of environmental regulations and heterogeneous influence on "green" productivity: evidence from china," Ecological Economics, vol. 132, pp. 104-112, 2017.

[14] A. Ebenstein, "The consequences of industrialization: evidence from water pollution and digestive cancers in China," Review of Economics and Statistics, vol. 94, no. 1, pp. 186-201, 2012.

[15] Y. Zhang, P. Jin, and D. Feng, "Does civil environmental protection force the growth of China's industrial green productivity? Evidence from the perspective of rent-seeking," Ecological Indicators, vol. 51, pp. 215-227, 2015.

[16] A. Charnes, W. W. Cooper, and E. Rhodes, "Measuring the efficiency of decision making units," European Journal of Operational Research, vol. 2, no. 6, pp. 429-444, 1978.

[17] R. G. Chambers, Y. Chung, and R. Färe, "Benefit and distance functions," Journal of Economic Theory, vol. 70, no. 2, pp. 407-419, 1996.

[18] R. Färe, S. Grosskopf, and C. A. Pasurka Jr., "Accounting for air pollution emissions in measures of state manufacturing productivity growth," Journal of Regional Science, vol. 41, no. 3, pp. 381-409, 2001.

[19] D.-H. Oh and A. Heshmati, "A sequential MalmquistLuenberger productivity index: environmentally sensitive productivity growth considering the progressive nature of technology," Energy Economics, vol. 32, no. 6, pp. 1345-1355, 2010.

[20] A. Emrouznejad and G.-L. Yang, " $\mathrm{CO}_{2}$ emissions reduction of Chinese light manufacturing industries: a novel RAM-based global Malmquist-Luenberger productivity index," Energy Policy, vol. 96, pp. 397-410, 2016.

[21] K. Tone and M. Tsutsui, "An epsilon-based measure of efficiency in DEA-a third pole of technical efficiency," European Journal of Operational Research, vol. 207, no. 3, pp. 15541563, 2010.

[22] D.-H. Oh and J.-D. Lee, "A metafrontier approach for measuring Malmquist productivity index," Empirical Economics, vol. 38, no. 1, pp. 47-64, 2010.

[23] K. De Witte and R. C. Marques, "Capturing the environment, a metafrontier approach to the drinking water sector," International Transactions in Operational Research, vol. 16, no. 2, pp. 257-271, 2009.

[24] M. Shahiduzzaman and K. Alam, "Information technology and its changing roles to economic growth and productivity in Australia," Telecommunications Policy, vol. 38, no. 2, pp. 125-135, 2014.

[25] C. Davis and K.-I. Hashimoto, "Patterns of technology, industry concentration, and productivity growth without scale effects," Journal of Economic Dynamics and Control, vol. 40, pp. 266-278, 2014.

[26] L. Zhang, "The knowledge spillover effects of FDI on the productivity and efficiency of research activities in China," China Economic Review, vol. 42, pp. 1-14, 2017.

[27] S. Bond, A. Hoeffler, and J. Temple, "GMM estimation of empirical growth models," Econometric Reviews, vol. 19, no. 3, pp. 321-340, 2000.

[28] F. Windmeijer, "A finite sample correction for the variance of linear efficient two-step GMM estimators," Journal of Econometrics, vol. 126, no. 1, pp. 25-51, 2005.

[29] Y. H. Chung, R. Färe, and S. Grosskopf, "Productivity and undesirable outputs: a directional distance function approach," Journal of Environmental Management, vol. 51, no. 3, pp. 229-240, 1997.

[30] R. Fare, S. Grosskopf, and C. Pasurkajr, "Environmental production functions and environmental directional distance functions," Energy, vol. 32, no. 7, pp. 1055-1066, 2007.

[31] R. Sala-Garrido, M. Molinos-Senante, and F. HernándezSancho, "Comparing the efficiency of wastewater treatment technologies through a DEA metafrontier model," Chemical Engineering Journal, vol. 173, no. 3, pp. 766-772, 2011.

[32] A. Hernández-Sancho, D. Lee, J. Hwang, and J. Shin, “influence of regulations on the efficiency of telecommunications operators: a meta-frontier analysis," Telecommunications Policy, vol. 37, no. 11, pp. 1071-1082, 2013.

[33] S. Munisamy and B. Arabi, "Eco-efficiency change in power plants: using a slacks-based measure for the meta-frontier Malmquist-Luenberger productivity index," Journal of Cleaner Production, vol. 105, pp. 218-232, 2015.

[34] K.-H. Chen and H.-Y. Yang, "A cross-country comparison of productivity growth using the generalised metafrontier Malmquist productivity index: with application to banking industries in Taiwan and China," Journal of Productivity Analysis, vol. 35, no. 3, pp. 197-212, 2011.

[35] H. J. Shan, "Re-estimation of China's capital stock K: 1952-2006," Journal of Quantitative and Technical Economics, vol. 25 , no. 10, pp. 17-31, 2008.

[36] M. Iosifidi, "Environmental awareness, consumption, and labor supply: empirical evidence from household survey data," Ecological Economics, vol. 129, pp. 1-11, 2016.

[37] Y. Simsekli, "An implementation to raise environmental awareness of elementary education students," Procedia-Social and Behavioral Sciences, vol. 191, pp. 222-226, 2015.

[38] C. Newman, J. Rand, T. Rand, and F. Tarp, "Technology transfers, foreign investment and productivity spillovers," European Economic Review, vol. 76, pp. 168-187, 2015. 

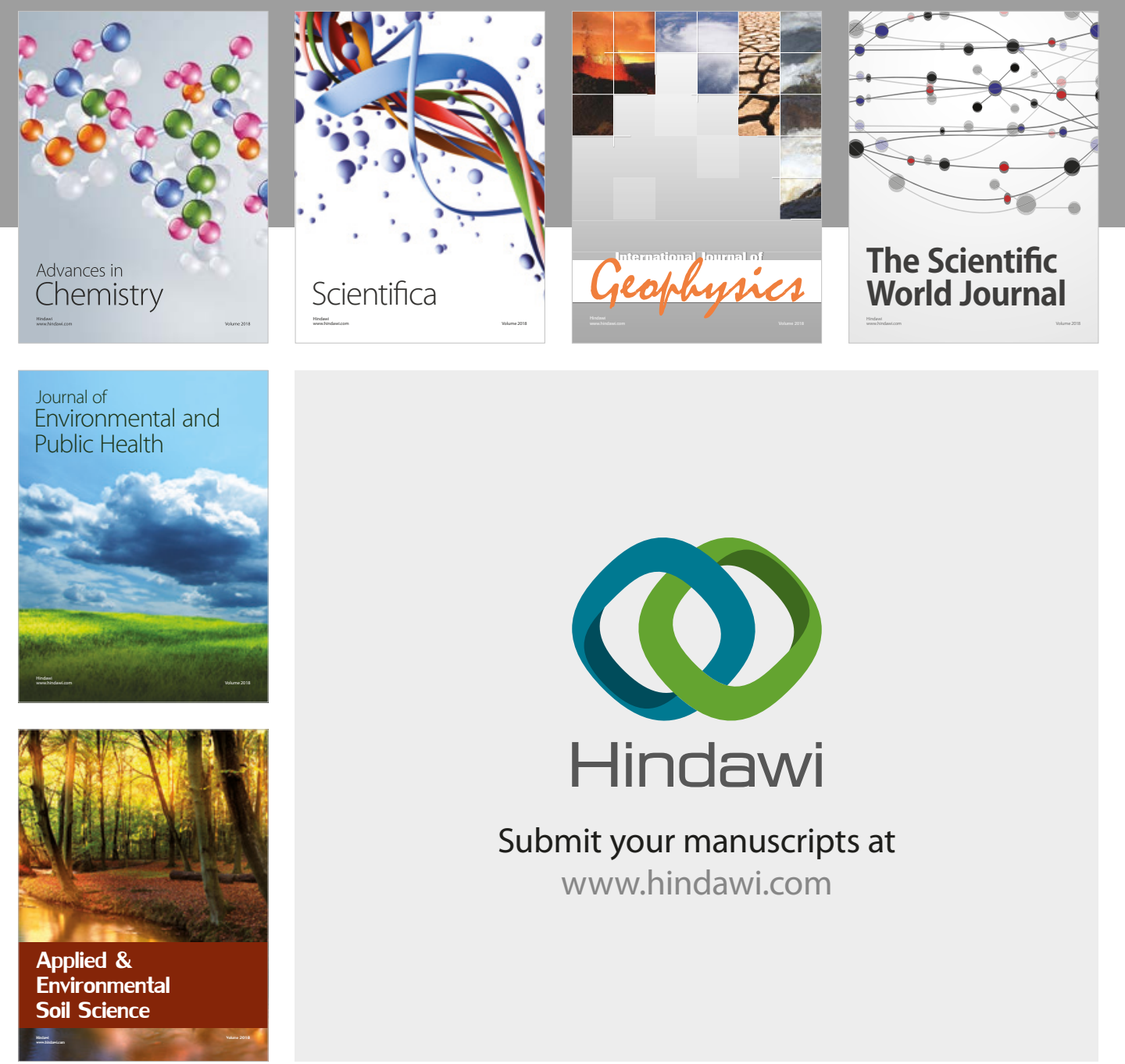

The Scientific

\section{World Journal}
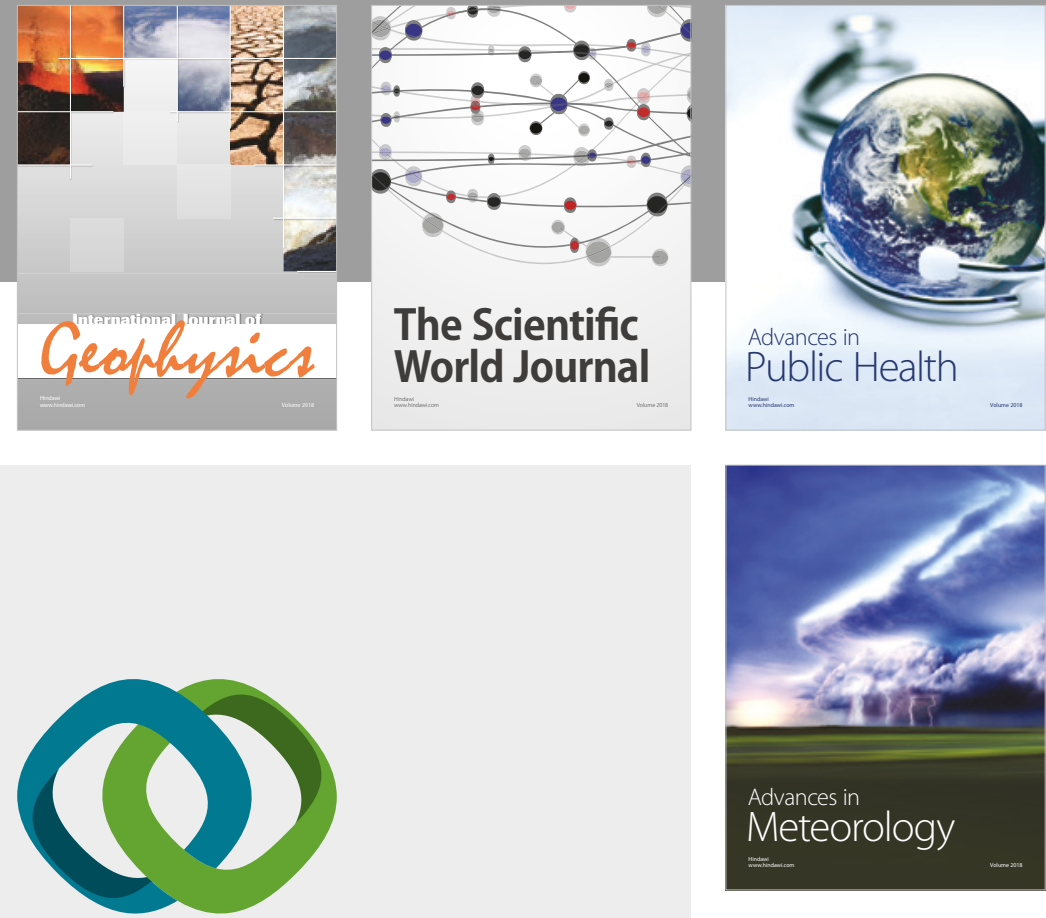

Advan

Public Health

\section{Hindawi}

Submit your manuscripts at

www.hindawi.com
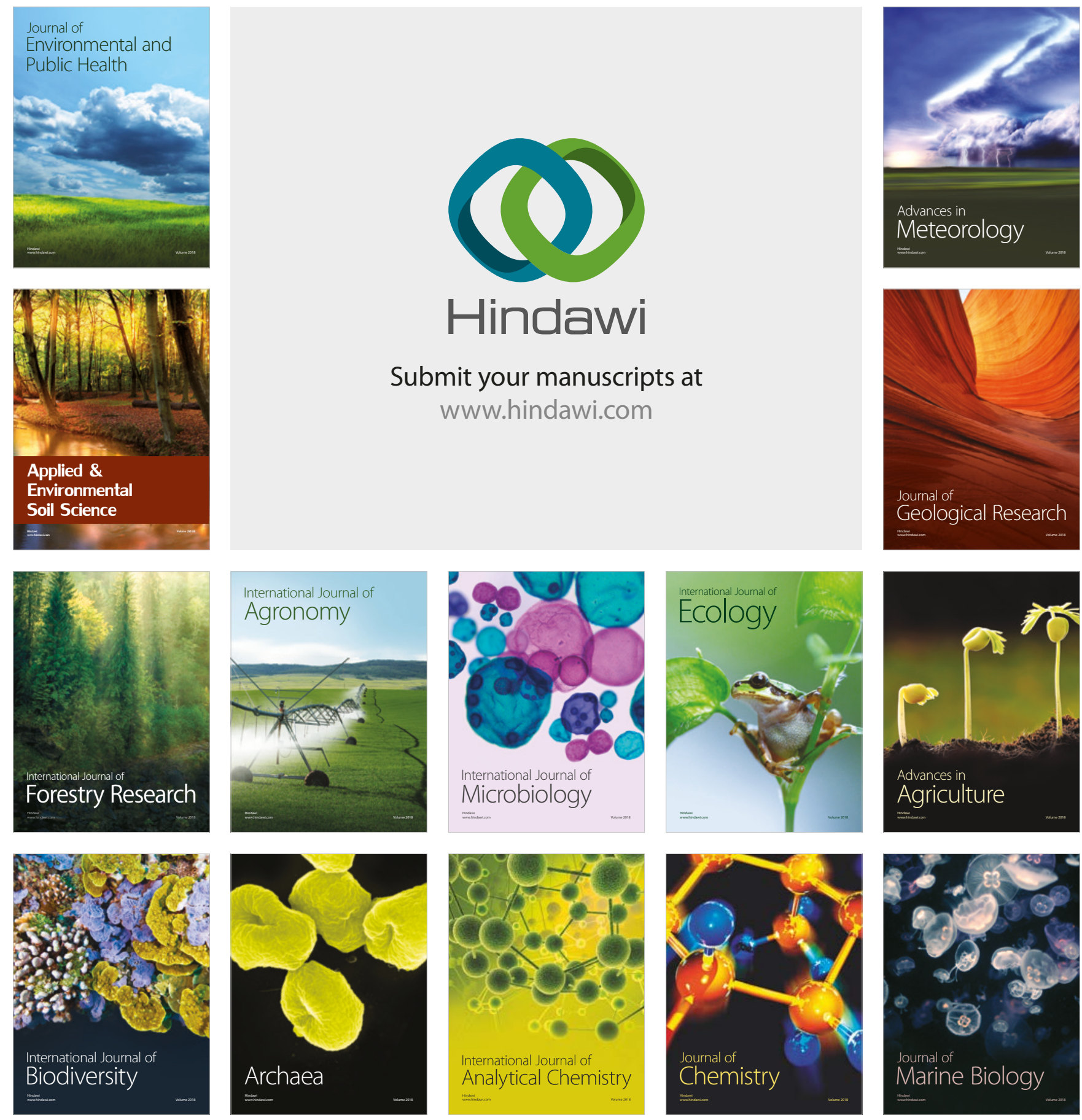